\title{
Research on Quality Infrastructure Evaluation of Mechanical Manufacturing Enterprise Based on ANP- Fuzzy
}

\author{
Yuhong Sun \\ Guangzhou College of Technology and Business \\ Guangzhou, China
}

\author{
Zhiteng Gao \\ Nanjing University of Aeronautics and Astronautics \\ Nanjing, China
}

\author{
Zongguang Wang \\ Lanzhou University of Technology \\ Lanzhou, China
}

\begin{abstract}
Quality infrastructure is an important technical means for enterprise to improve productivity, protect consumer rights, maintain safety and improve quality. As an "industrial heart", machinery manufacturing enterprises play an autonomy role in the development of the national economy. A quality infrastructure evaluation index system for mechanical manufacturing enterprise is established to evaluate the level of quality infrastructure for machinery manufacturing enterprise. Based on the results of basic research on quality technology in China and foreign countries, the principle of Analytic Network Process (ANP) is applied. ANP-Fuzzy method is used to evaluate the quality infrastructure capabilities of the mechanical manufacturing enterprise under the auxiliary operation of Super Decisions software. The results show that the certification of quality management system, product quality grade rate, and product supervision and inspection pass rate account for a large proportion in the overall evaluation system, which play a decisive role in the mechanical manufacturing enterprise quality infrastructure evaluation.
\end{abstract}

Keywords-machinery manufacturing enterprise; quality infrastructure; ANP-Fuzzy

\section{INTRODUCTION}

The quality infrastructure refers to the general term for the establishment and implementation of the quality system framework required for standardization, metrology, inspection and testing, and certification. Since the introduction of United Nations Conference on Trade and Development (UNCTAD) and World Trade Organization (WTO) in 2005, it has developed rapidly in the international arena and will become a supporting force for the sustainable development of the world economy in the future. Major developed countries and regions in the world have incorporated them into national development strategies, such as the US "Innovation Strategy", Germany "Industry 4.0", EU "Horizon 2020 Plan" [1], Association of Southeast Asian Nations (ASEAN) and emerging economies such as India and Brazil have adopted a series of measures to strengthen the national quality infrastructure, promote quality improvement and strengthen industrial competitiveness [2].

As an "industrial heart", Chinese mechanical manufacturing enterprises have leapt to the top in the world in terms of the scale. The pace of "going out" of manufacturing enterprises has been greatly accelerated. However, from the perspective of the world machinery industry system, China is a big country in machinery manufacturing, not a strong country in mechanical production. The problems of low-quality products, low technical level, weak market competitiveness and weak independent innovation ability of machinery manufacturing enterprises are outstanding [3]. Therefore, how to strengthen the control and management of the quality infrastructure of machinery manufacturing enterprises, adapt to the new trend of the Party Central Committee to "promote the structural reform of the supply side, focus on improving the supply efficiency and quality of the supply system", and improve the basic level of quality technology has become the machinery manufacturing industry's key issues of general concern.

\section{CONSTRUCTION OF QUALITY INFRASTRUCTURE EVALUATION INDEX SYSTEM OF MECHANICAL ENTERPRISE}

Nowadays, some scholars abroad have studied the quality infrastructure. For example, Guasch J L (2007) puts forward the competitive advantages and standards of the enterprise quality infrastructure [4]. Racine J L (2011) constructed a quality infrastructure model from the perspectives of standardization, metrology, inspection and testing, and certification, also empirically studied the quality infrastructure through the analysis of Eastern European and Central Asian data [5]. Harmes-Liedtke U, Matte JJOD (2011) proposed methodological measures for measuring national quality infrastructure by studying the capabilities of standardization, metrology, inspection and testing, and accreditation in 53 different countries around the world [6]. 
From the domestic situation, most of the domestic research is limited to various specific aspects of the basic work of quality infrastructure (including evaluation of standardization, metrology, inspection and testing, and certification). China is also preparing to "design and develop the national quality infrastructure evaluation index system and indexation evaluation model", and extensively launched the "Enterprise Quality Infrastructure Situation Questionnaire" nationwide. But there are few methods to comprehensively evaluate the basic capabilities of quality technology in the research field. This work draws on the research results of domestic and foreign scholars on the quality infrastructure, and combines the status quo of the quality infrastructure capabilities of mechanical manufacturing enterprise, adheres to the principles of comprehensive, systematic, scientific, operable and universal to construct the following evaluation index system, as show in "Fig. 1".

\section{The quality infrastructure capabilities of mechanical manufacturing enterprise $\mathbf{0}$}

\begin{tabular}{|c|c|c|c|c|c|c|c|c|c|c|c|c|c|c|c|c|c|c|c|}
\hline \multicolumn{3}{|c|}{\begin{tabular}{|c} 
Standardization \\
A
\end{tabular}} & \multicolumn{5}{|c|}{$\begin{array}{c}\text { Metrology } \\
\text { B }\end{array}$} & \multicolumn{3}{|c|}{$\begin{array}{c}\text { Inspection and } \\
\text { testing C }\end{array}$} & \multicolumn{3}{|c|}{\begin{tabular}{|c|}
$\begin{array}{c}\text { Certification } \\
\mathrm{D}\end{array}$ \\
\end{tabular}} & \multicolumn{6}{|c|}{$\begin{array}{l}\text { Basic resources and } \\
\text { cultural construction } \mathrm{E}\end{array}$} \\
\hline 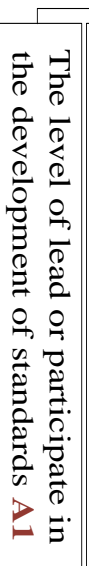 & 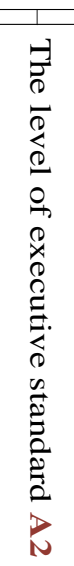 & 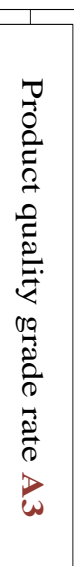 & 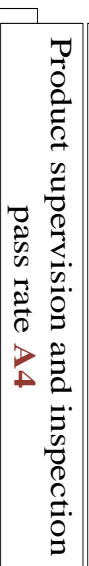 & 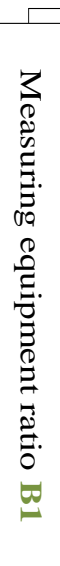 & 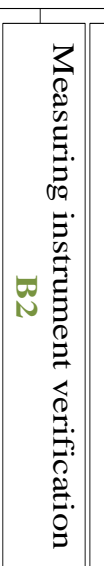 & 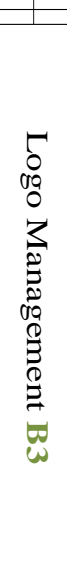 & 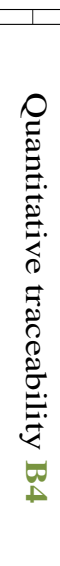 & 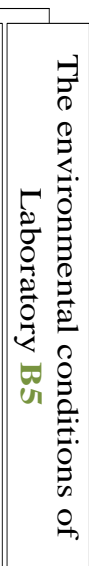 & 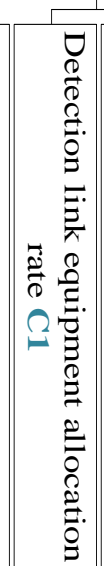 & 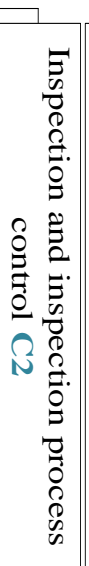 & 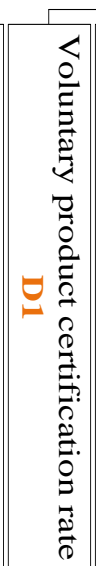 & 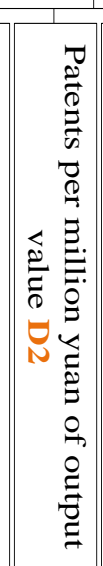 & 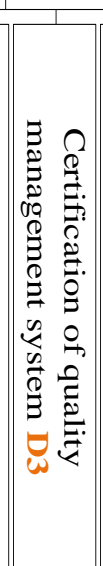 & 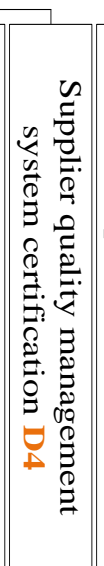 & 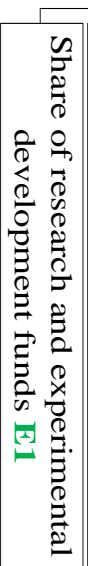 & 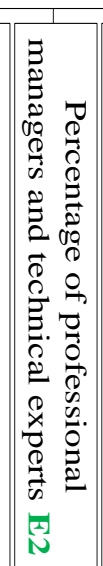 & 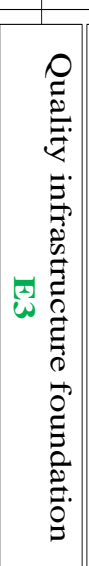 & 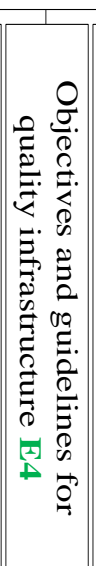 & 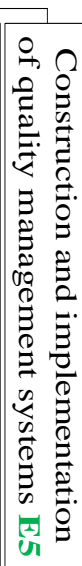 \\
\hline
\end{tabular}

Fig. 1. Quality infrastructure index system of mechanical manufacturing enterprise.

\section{ANP-FUZZY ANALYSIS OF THE QUALITY} INFRASTRUCTURE OF MECHANICAL ENTERPRISE

The fuzzy comprehensive evaluation is a method that uses the principle of fuzzy mathematics to quantify the factors with unclear boundaries and difficult to quantify, and comprehensively evaluates the ranks of the evaluated things from multiple factors. The enterprise quality infrastructure ability has such ambiguous characteristics, so the fuzzy comprehensive evaluation method can be used.

\section{A. Fuzzy Implementation Steps}

The fuzzy implementation steps include: clarify each factor set and evaluation level for the evaluation object; calculate the weight of each factor and its membership degree respectively, and obtain the fuzzy matrix of each level; compute the fuzzy matrix of each level and the weight vector of the corresponding factor, and achieve normalization. Based on the fuzzy comprehensive evaluation results of dimensional indexes, the target fuzzy comprehensive evaluation results are obtained. The specific implementation steps are shown in "Fig. 2".

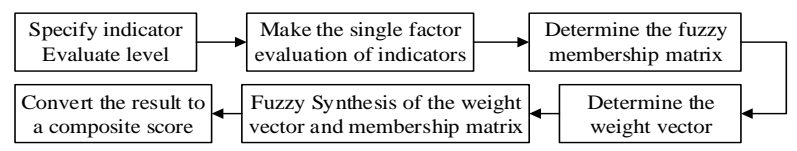

Fig. 2. Fuzzy comprehensive evaluation implementation steps.

\section{B. Determination of Weight Factors}

The basic evaluation index system of quality infrastructure of mechanical enterprises is a progressive hierarchical structure, and the weight of each index can be realized by the network analytic hierarchy process. ANP is a decision-making method that was proposed by Prof. T.L. Saaty of the University of Pittsburgh in the United States in 1996 to adapt to non-independent hierarchical structures [7]. It is a new practical decision-making method based on analytic hierarchy process (AHP). By establishing the network structure model of the evaluation index system, it uses limit matrix to comprehensively analyze the interacting node to finally obtain the mixed weight of the index. The typical ANP structure is shown in "Fig. 3". 

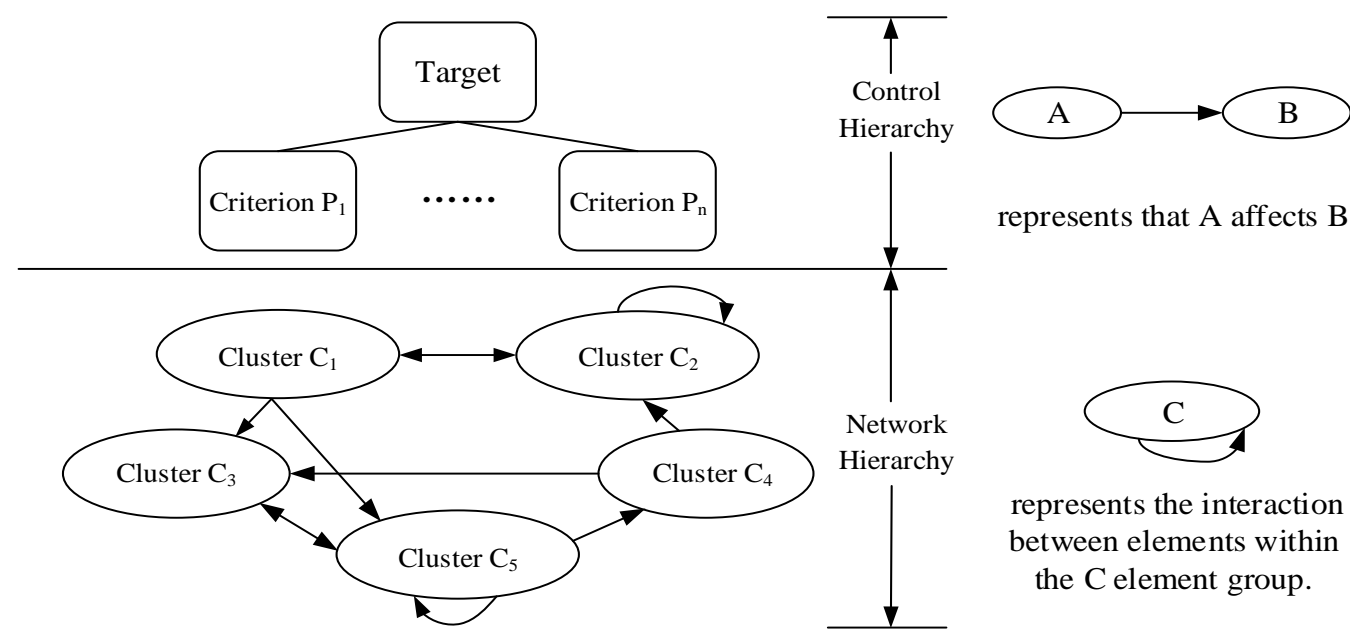

represents that $\mathrm{A}$ affects $\mathrm{B}$

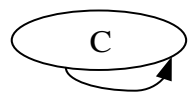

represents the interaction between elements within the $\mathrm{C}$ element group.

Fig. 3. Typical ANP structure diagram.

The ANP calculation process is more complex. In practice, it often uses Super Decisions (SD) software to calculate the weight of indexes.

\section{EMPIRICAL ANALYSIS}

According to the above evaluation steps, the following is an example analysis by Jiuquan OK Seed Machinery Co., Ltd., a typical machinery manufacturing enterprise in Gansu, China. Various methods are used to collect measurement data of indexes in accordance with the principles of convenience and truth, including statistical reports, document inspections, meeting minutes, questionnaires, etc.

\section{A. Construction of ANP Model}

The network structure model is constructed based on the correlation analysis of the evaluation indexes, as shown in "Fig. 4".

TABLE I. WEIGHT OF INDEXES

\begin{tabular}{|c|c|c|c|c|c|c|c|}
\hline Dimension & Dimension weight & Node & Node weight & Dimension & Dimension weight & Node & Node weight \\
\hline \multirow{4}{*}{ A } & \multirow{4}{*}{0.344} & A1 & 0.005 & \multirow{4}{*}{$\mathrm{D}$} & \multirow{4}{*}{0.198} & D1 & 0.002 \\
\hline & & A2 & 0.004 & & & D2 & 0.003 \\
\hline & & A3 & 0.171 & & & D3 & 0.191 \\
\hline & & A4 & 0.164 & & & D4 & 0.002 \\
\hline \multirow{5}{*}{ B } & \multirow{5}{*}{0.226} & B1 & 0.065 & \multirow{5}{*}{$\mathrm{E}$} & \multirow{5}{*}{0.134} & E1 & 0.004 \\
\hline & & B2 & 0.081 & & & E2 & 0.065 \\
\hline & & B3 & 0.045 & & & E3 & 0.006 \\
\hline & & B4 & 0.015 & & & E4 & 0.039 \\
\hline & & B5 & 0.02 & & & E5 & 0.02 \\
\hline \multirow{2}{*}{$\mathrm{C}$} & \multirow{2}{*}{0.098} & $\mathrm{C} 1$ & 0.038 & & & & \\
\hline & & $\mathrm{C} 2$ & 0.06 & & & & \\
\hline
\end{tabular}




\section{Determination of Evaluation Level}

Based on the collected index data, the experts judged the grades of the quality infrastructure capabilities of Jiuquan OK Seed Machinery Co., Ltd. to form a review set V, which is determined by the ratio of the number of people judged to that level as the total number of people:

$$
V=\left\{v_{1}, v_{2}, v_{3}, v_{4}, v_{5}\right\}
$$

\section{Fuzzy Comprehensive Evaluation Results}

First, dimension index layer. Taking the enterprise standardization " $A$ " as an example, the specific application method of the formula is explained. Using the fuzzy synthesis operator:

$$
B=W * R(M(*, \oplus))
$$

where $*$ is the operator symbol. The calculation is as follows:

$$
\begin{aligned}
B_{A} & =W_{A} \cdot R_{A}=W_{A} \cdot\left(V_{1}, V_{2}, V_{3}, V_{4}, V_{5}\right) \\
& =\left(\begin{array}{lllll}
0.005 & 0.004 & 0.171 & 0.164
\end{array}\right) \\
& \cdot\left[\begin{array}{lllll}
0.100 & 0.233 & 0.500 & 0.100 & 0.067 \\
0.000 & 0.033 & 0.400 & 0.300 & 0.267 \\
0.000 & 0.000 & 0.000 & 0.500 & 0.500 \\
0.000 & 0.000 & 0.033 & 0.500 & 0.467
\end{array}\right]
\end{aligned}
$$

The results of the normalized operation are:

$$
B_{A}=[0.002,0.005,0.037,0.333,0.624]
$$

Similarly, other dimensional index fuzzy comprehensive evaluation vectors (after normalization) are available.

Second is target layer. The target layer fuzzy comprehensive evaluation matrix is:

$$
R=\left[B_{A}, B_{B}, B_{C}, B_{C}, B_{E}\right]^{T}
$$

The results of the target layer fuzzy comprehensive evaluation are as follows:

$$
B=W_{\mathrm{O}} * R=(0.019,0.109,0.234,0.251,0.387)
$$

Further, the target layer fuzzy comprehensive evaluation score is calculated by the follows:

$$
\begin{aligned}
O & =\sum_{j}^{n} b_{j} \cdot V\left(v_{j}\right) / \sum_{j}^{n} b_{j}=V \cdot B^{T} \\
& =\left(\begin{array}{lllll}
20 & 40 & 60 & 80 & 100
\end{array}\right) \cdot B^{T}=77.53
\end{aligned}
$$

The results of the comprehensive evaluation show that Jiuquan OK Seed Machinery Co., Ltd. has a comprehensive score of 77.53, which is at a general level. The specific analysis shows that its standardization ability, basic resources and cultural construction are all affiliated to the "general" level, which has become a short-term constraint on the improvement of the quality infrastructure. The enterprise should fully absorb the advanced experience of the same industry and pay attention to the improvement of standardization, basic resources and cultural construction.

\section{CONCLUSION}

Through the analysis of ANP-Fuzzy, the evaluation model of the quality infrastructure of mechanical enterprises is constructed. It is beneficial for enterprises to examine their own quality infrastructure ability more accurately, and to complement each other, thereby enhancing the competitiveness of machinery manufacturing enterprises in the fierce market environment. From the point of view of application effect, the fuzzy comprehensive evaluation model proposed in this work has the characteristics of rationality of evaluation index system, scientific determination of evaluation index weight, and evaluation effectiveness.

\section{ACKNOWLEDGMENT}

This work was funded jointly by the Guangzhou College of Technology and Business 2019 Research Project (Grant No. KA201912), the National Natural Science Foundation of China (Grant No. 71761026), and the Ministry of Education Enterprise Collaborative Education Project (Grant No. 201701043007). All calculations were carried out using the equipment provided by Gansu Provincial Computing Center.

\section{REFERENCES}

[1] S. P. Zhi, "Research on national quality infrastructure construction under the new normal," China Leadership Science, vol.07, pp. 9-12, 2016.

[2] T. T. Li, "International experience analysis and enlightenment of national quality and technology infrastructure construction," China Quality Certification, vol.11, pp. 47-48, 2018

[3] R. F. Wang, "Research on quality control and management methods of machinery manufacturing enterprises in China," Manager' Journal, vol.16, pp.188-192, 2016

[4] J. L. Guasch, "Quality systems and standards for a competitive edge", World Bank Publications, pp. 219-281, 2007.

[5] J. L. Racine. "Harnessing quality for global competitiveness in Eastern Europe and Central Asia", World Bank Publications, pp. 105150, 2011.

[6] U. Harmes-Liedtke, J. D. Matteo, "Measurement of quality infrastructure," Braunschweig: $\quad$ Physikalisch-Technische Bundesanstalt. pp. 5-9, 2011

[7] T. L. Saaty, "Decision making with the analytic network process (ANP) and its Super Decisions Software: The National Missile Defense (NMD) Example," ISAHP 2001 Proceedings, Bern, Switzerland, pp. 2-4, August, 2001 